\title{
A Study on the Motivation and Demand of College Students' Volunteer Tourism: A Case Study of Shenzhen College Students
}

\author{
Du Peng ${ }^{1, a}$, Huang Xiaoyi ${ }^{2, b}$
}

${ }^{1}$ Nanhai Ave 3688, Shenzhen, Guangdong, P.R.China, 518060

${ }^{2}$ Nanhai Ave 3688, Shenzhen, Guangdong, P.R.China, 518060

adpng1982@szu.edu.cn, bhm1ny@qq.com

Keywords: Volunteer Tourism, Motivation, Demand, College Students, Shenzhen.

Abstract. Volunteer tourism has become one of the major public interest activities of college students with a lot of attributes, such as charity service, self-promotion, travel experience, green ecology, and education poverty alleviation and so on. Taking college students of Shenzhen as the research object, this paper uses interviews and content analysis methods to sum up the motivation, preferences and constraints to participate in volunteer tourism. The study found that college participations prefer diversified, experiential, social and unique volunteer tourism projects. The cost of money and time, safety insurance, communication and social identification are the most concentrated concerns of respondents. At last, the paper puts forward the development strategy of college students' volunteer tourism, which has a certain practical significance to promote the sustainable development of tourism.

\section{大学生公益旅游动机与需求调查研究-以深圳大学生为例 \\ 杜鹏1, a , 黄晓怡1,b \\ 1深圳大学师范学院, 南山区, 深圳, 广东, 中国 \\ adpng1982@szu.edu.cn, bhm1ny@qq.com}

关键词: 公益旅游; 动机; 需求; 大学生; 深圳

摘要. 公益旅游具有公益服务、自我提升、出行体验、绿色生态、教育交流等诸多属性, 成为 大学生关注和参与的主要公益活动之一。本文以深圳大学生群体为研究对象, 访谈法和内容 分析法为主要研究方法, 总结归纳大学生参与公益旅游的动机需求、行为偏好和约束顾虑特 征。研究发现深圳大学生公益旅游的参与特征呈现多样化、体验化、网络化和个性化的特征, 能够体现大学生特长和价值的项目更受青睐, 而费用、时间、安全、沟通障碍是被访者反映 较为集中的顾虑。最后, 本文并提出大学生公益旅游发展策略, 对促进公益旅游在全国大学 生群体中持续发展具有一定现实意义。

\section{1. 引言}

20 世纪80年代，人们对环境问题的关注已经开始影响消费行为，绿色、可替代、可持续 性的旅游方式逐渐推动了公益旅游（Volunteer Tourism）的发展和普及 ${ }^{[1]}$ 。公益旅游可以定 义为旅游者将时间、资金和劳动力投入到离自己生活环境较远的目的地，并以此获得独特的 文化、环境和精神收获的过程 ${ }^{2]}$ 。对于参与者，公益旅游是旅游休闲、节约成本、体验参 与、开拓眼界、自我提升、社会价值认同等多元化目标的交集; 对于服务对象，公益旅游具 
有保护、救助和帮扶发展的功能。目前常见的公益旅游项目主要包括: 扶贫助学、生态环境 保护、非物质文化遗产保护，以及目的地卫生、教育、文化改善项目等类型 ${ }^{[3]}$ 。

目前公益旅游主要的研究成果集中于公益旅游的动机、商业化、媒介组织等环节和内容。 Callanan等学者将公益旅游志愿者分为三个群类: 浅度旅游志愿者、中度旅游志愿者、深度旅 游志愿者, 相对而言浅度旅游志愿者更关注自身价值和职业提升, 公益旅游的参与程度也会 随着志愿活动的发展和志愿者的成长而发生转变 ${ }^{[4]}$ 。公益旅游需要旅游志愿者拥有较多的时 间、经济条件相对充裕, 还需要对旅游和公益活动充满热情。虽然我国经济发展近年成果显 著, 但相对西方而言, 我国公益旅游大众化普及还刚刚起步 ${ }^{[5]}$ 。社会经济仍不平衡, 现代公益 和社会体系并未完全形较, 公益服务对政府的依赖度较高, 还没有成熟的志愿服务文化和社 会认同体系都是公益旅游在我国进一步推进的阻力 ${ }^{[6]}$ 。

大学生是公益旅游最重要的参与群体之一。公益旅游有利于培养大学生的社会责任感, 成为锻炼与自我提升、社会交往、拓展视野、认知社会的重要选择。虽然目前公益旅游在大 学生中参与比例不高, 但覆盖范围和领域都在快速发展。沿海开放地区和特大型城市的大学 生较早参与公益旅游活动, 极可能是公益旅游参与体验着者和创新者, 具有一定的代表性。

本研究主要使用访谈调查和内容分析方法, 以深圳大学生群体中的公益旅游体验者为主 要调查研究对象, 聚焦城市大学生群体参与公益旅游动机、需求和约束特征, 并针对性的提 出大学生公益旅游发展与推进机制, 有助于探究中国近3000万大学生群体融入公益旅游服务 的动机、收获、障碍和渠道, 推动公益旅游在中国社会的发展。

\section{2. 研究方法与访谈调查}

本研究以访谈调查和定性研究方法为主, 并通过内容分析了解大学生公益旅游的动机、 障碍和约束, 并提出相应的发展策略。本研究选择我国经济较发达地区的深圳大学生作为调 查对象, 具有一定的针对性和前瞻性。

研究访谈对象为在校大学生和近三年大学毕业学生, 范围相对集中, 本次访谈样本共 12 人。主要访谈内容主要包括: 公益旅游动机、约束限制和参与渠道等内容, 每个方面又会细 分为多个层面的子问题, 引导被访者深度反映参与公益旅游的相关情况。

\section{3. 大学生公益旅游的动机与约束}

\section{1大学生公益旅游的动机}

（1）公益服务与帮助他人

文化与环境保护。文化和环境保护是多数受访者提到的参与公益旅游的动机。被访者希 望通过自身技能和专业帮助改善和保护目的地环境，了解当地传统文化，并通过传播推广。

直接帮助他人。几乎所有受访者都希望通过公益旅游帮助目的地居民, 特别是儿童, 这 可能与大学生主要参与支教类公益项目有关。

被访者Z同学: “希望能够通过参与公益旅游, 实地考察当地的环境。”

被访者 $\mathrm{G}$ 同学: “当时参与到公益旅游当中很大的一部分原因就是为了要实现帮助困难 儿童读书困难的愿望，更希望的是能够亲自去提供帮助而不只是金钱上的资助。”

(2) 独特体验与兴趣爱好

独特真实的生活体验。大部分被访者参加公益旅游希望获得真实独特的生活体验, 而并 非观光式旅游和简单的物资捐赠。

被访者L同学表示: “我想自己去那里体验得到的真实的不一样的生活”。

被访者Z同学表示: “公益旅游最大的不同, 就是和他们（居民）一起吃东西聊天。”

特定目的地自然、文化、宗教兴趣。访谈中部分受访者是对旅游目的地特殊文化、宗教、 自然风光和社会问题较为感兴趣, 在公益服务的过程中不断学习和体验。

被访者 $\mathrm{ZH}$ 同学表示: “因为目的地在巴基斯坦而对公益旅游产生了浓厚的兴趣” 


\section{（3）自我价值实现}

自我挑战与认同需求。部分受访者表示公益旅游是有价值和意义的人生挑战。

被访者Y同学表示 “希望 (趁) 还比较年轻, 能做一些让自己身边人觉得了不起事”。 被访者 $\mathrm{H}$ 同学则认为“未知的环境和艰苦的环境能让自己更有成就感”。

丰富阅历与自我提升。大学生在倾向于通过公益旅游来实现自我价值的提升, 同时获取 社会、文化等方面知识，丰富阅历、锻炼能力、开拓眼界。

被访者 $\mathrm{H}$ 同学表示: “参与公益旅游不仅给予了帮助, 我们也从中得到成就感和幸福”。 被访者 $\mathrm{ZH}$ 同学表示: “公益旅游本身就是无形的知识与帮助, 对我的成长非常有帮助。”

学业与出国深造。大学生参与公益旅游除了要满足自身的需求外, 更是希望能对日后工 作和留学申请有所帮助, 在简历上能够与众不同。但大多数受访者均表示, 这只是参与公益 旅游的附加动机，即使没有这方面的回报，他们也会参与公益旅游。

(4) 公益旅游的社交动力吸引力

社交互动与文化交流吸引。大学生具有一定的社交和文化互动欲望, 志愿者旅游能够更 加深入的与当地居民进行交流互动，比普通游客获得更多的接触当地文化的可能性。

被访者 $\mathrm{G}$ 同学表示: “公益旅游能 (让我) 认识更多的人, 了解他们的生活, 甚至可能和 他们成为朋友”。

人际关系网络的推动。大学生们希望与更多志同道合的同龄人、同学和亲友 (男女朋友) 共同参与到公益旅游，在相互交流的同时体验公益旅游的意义。

被访者 L同学表示: “熟悉的人参加公益旅游能够降低恐惧感, 能够更快的融入和参与”。

\section{2大学生公益旅游参与偏好}

\section{（1）信息获取与参与渠道}

多数的受访者通过学校的相关组织和亲友推荐参与公益旅游。此外, 社交媒体、公众号 等也成为大学生获取公益旅游信息的重要渠道。

（2）服务内容选择

大学生普遍反映希望公益旅游的项目能够和自身的优点以及学识结合起来。访谈对象参 与公益旅游项目绝大多数以支教服务类活动, 部分受访者表示公益旅游能发挥他们教育、摄 影、外语等方面的知识和技能。

(3) 组织机构与品牌

目前大学生参与公益旅游的相关组织包括校内的组织, 校外组织, 政府部门组织, 商业 运作组织。公益旅游的参与者对组织机构或合作伙伴有一定要求, 除了产品内容外, 在学生 群体中拥有较好品牌口碑的公益组织和项目成为学生的优先选择。

\section{3 大学生公益旅游顾虑与约束}

\section{（1）费用与时间约束}

大学生没有固定的经济收入, 支付公益旅游的直接费用有一定的压力, 成为大学生加入 公益旅游的重要约束和障碍。虽然多数受访者表示能够承受, 但觉得帮助和公益还需要支付 费用并不合理。此外多数被访者表示项目在假期并持续时间少于 1 个月能够接受; 超过 1 周的 公益旅游项目均是在暑假期间完成, 而短期项目供给相对缺失。

(2) 风险与安全顾虑

多数被访者表示对公益风险均有心理和知识储备, 但仍有担心和顾虑, 这些风险也直接 影响家庭对其出行的支持。此外, 被访者对于生活条件不足都有预期, 对出游成型影响较 小。

(3) 家庭和社会认同障碍

受访者家长多对其参与公益活动表示认同, 并能支持提供部分开销, 但对安全顾虑较 多。合理、安全、可靠和特色的组织机构和项目成为家庭支持大学生公益旅游的重要参考因 素。 


\section{4.大学生公益旅游发展策略}

\section{1校园公益旅游开展策略}

学校内部和公益组织可设置优秀公益志愿者奖学金体系，补贴志愿者的直接费用支出。 此外, 通过设定一定比例的大学生公益实践学分, 鼓励学生参与公益旅游。学校还可与相关 组织合作, 结合大学生需求特点开设公益旅游讲座与课程, 宣传公益旅游文化和精神。

\section{2项目策划组织单位}

降低出行风险。鼓励公益旅游组织单位、政府、高校与专业机构合作，降低项目风险; 科学培训、心理疏导和商业保险，也是降低公益旅游不确定性的重要措施。

丰富产品设计。公益旅游可以根据参与者的不同的需求, 合理安排公益与旅游的比例和 时间，降低进入门槛。

立体宣传推广。公益旅游组织在大学生中宣传时, 除了通过网络和纸质的宣传之外, 线 下还可以通过讲座、分享会、课堂教学、直播和社交等方式进行推广。

\section{3政府与社会}

完善资金支持平台。结合网络技术优势，形成资金支持平台，有助于众筹资金、监督管 理、信息共享、经验分享，减少信息不对称，降低费用成本对大学生公益旅游的约束。

构建风险评估系统。政府或第三方机构应与公益旅游活动组织方共同建立项目风险评估 系统，提早完善风险应急预案，降低参与者和组织者对公益旅游项目信息不对称。

\section{5. 结束语}

本文以深圳大学生群体为研究对象, 以访谈法和内容分析法为主要研究方法, 总结归纳 大学生参与公益旅游的动机需求、行为偏好和约束顾虑。研究发现公益旅游概念在城市大学 生中已较为普及, 但实际参与比例仍然不高; 大学生公益旅游的参与特征呈现多样化、体验 化、网络化和个性化的特征, 其主要动机包括公益服务、体验生活、自我实现和社交互动等 方面；对于公益旅游项目的选择，被访者更倾向于能体现其自身价值和特长的项目，同时组 织机构的口碑也成为选择的重要依据; 而费用、时间、安全、沟通和社会认同是被访者反映 较为集中的顾虑。最后, 本文并提出大学生公益旅游发展策略, 对促进公益旅游持续发展具 有一定现实意义。

\section{References}

[1] Holden A, Environment and Tourism. Routledge, 2000.

[2] S Wearing, J Neil, SF Mccool, RN Moisey. Expanding sustainable tourism's conceptualization: ecotourism, volunteerism and serious leisure, 2001.

[3] ZONG Yuanyuan, A Review of the Researches on Voluntourism Motives, Experience and Impacts, Tourism Science, vol.26, pp.78-94, 2012.

[4] Callanan, M., \& Thomas, S. (2005), Chapter 15-volunteer tourism: deconstructing volunteer activities within a dynamic environment, Niche Tourism, pp.183-200, 2005.

[5] FU Yanan, HOU Guolin, LI Xincun. Progress and Implications in International Research of Volunteer Tourism, Tourism Tribune, vol.31, pp. 124-134, 2016.

[6] GUO Yang, CHAI Yi, WANG Yonggang, Research on the influence of the development of China's volunteer tourism and the measurement of demand potential, Inquiry Into Economic Issues, vol.16, pp. 57-60+81, 2013. 